\title{
Design and Synthesis of Pyrazole-3-one Derivatives as Hypoglycaemic Agents
}

\author{
Prasanna A. Datar and Sonali R. Jadhav \\ Department of Pharmaceutical Chemistry, Sinhgad Institute of Pharmacy, Pune, Maharashtra 411041, India \\ Correspondence should be addressed to Prasanna A. Datar; d_pras_anna@rediffmail.com
}

Received 21 September 2014; Accepted 5 November 2014

Academic Editor: Arie Zask

Copyright ( 2015 P. A. Datar and S. R. Jadhav. This is an open access article distributed under the Creative Commons Attribution License, which permits unrestricted use, distribution, and reproduction in any medium, provided the original work is properly cited.

Pyrazole-3-one compounds were designed on the basis of docking studies of previously reported antidiabetic pyrazole compounds. The amino acid residues found during docking studies were used as guidelines for the modification of aromatic substitutions on pyrazole-3-one structure. Depending on the docking score, the designed compounds were selectively prioritized for synthesis. The synthesized compounds were subjected to in vivo hypoglycemic activity using alloxan induced diabetic rats and metformin as a standard. Compound 4 having sulphonamide derivative was found to be the most potent compound among the series.

\section{Introduction}

Diabetes mellitus (DM) is a metabolic disorder resulting from a defect in insulin secretion, insulin action, or both. Insulin deficiency in turn leads to chronic hyperglycaemia with disturbances of carbohydrate, fat, and protein metabolism [1]. Diabetes is the most common endocrine disorder, that is, multifaceted condition that includes $\beta$-cell dysfunction, neurotransmitter dysfunction, decreased insulin secretion, decreased incretin effect, increased hepatic glucose production, increased glucagon secretion, decreased glucose uptake, peripheral insulin resistance, and elevated hepatic gluconeogenesis together with hypertension, dyslipidemia, obesity, and cardiovascular disease [2]. As the disease progresses, tissue or vascular damage ensues leading to severe diabetic complications such as retinopathy, neuropathy, and nephropathy [3]. The prevalence of diabetes is rising all over the world due to population growth, aging, urbanisation, and an increase of obesity and physical inactivity. The International Diabetes Federation (IDF) estimates the total number of people in India with diabetes to be around 50.8 million in 2010 rising to 87.0 million by 2030 [4]. Type 2 diabetes mellitus (T2DM) presents a major challenge to healthcare system around the world. The current oral treatment options for T2DM include metformin, sulfonylurea or thiazolidinedione derivatives, glycosidase inhibitors, and the recently dipeptidyl peptidase IV inhibitors which have been introduced. Antioxidants are used as supportive therapy in the treatment of DM and hypoglycemic plants have been shown to regulate the oxidative complications of DM [5].

Pyrazole derivatives are the subject of many research studies due to their widespread potential biological activities such as analgesic [6,7], antidiabetic [8], anticonvulsant [9], antimicrobial [10], anti-inflammatory [11], antiviral [12], and anticancer activities [13]. 1,5-Diarylpyrazole derivatives have been reported as nonnucleoside HIV-1 reverse transcriptase inhibitory activity [14]. Kees et al. [15] have described (4-substituted benzyl) (trifluoromethyl)pyrazoles and pyrazolones which represent a new class of antidiabetic compounds. Cottineau et al. [16] have reported substituted pyrazole-4-carboxylic acid and reported the pharmacophore 3-methoxy-1H-pyrazole-4-carboxylic acid ethyl ester as a hypoglycemic agent. Das et al. [17] have synthesized substituted pyrazole-3-one derivatives as potential hypoglycaemic agent.

\section{Experimental Methods}

2.1. Molecular Docking Study of Pyrazole Derivatives. Molecular docking studies were performed by using Glide v5.6 (Schrodinger, LLC) [18]. The X-ray crystal of peroxisome 
TABLE 1: Reported antidiabetic pyrazole-3-one compounds used for docking studies.

\begin{tabular}{lcccc}
\hline $\begin{array}{l}\text { Reference } \\
\text { compound }\end{array}$ & $\mathrm{R}_{1}$ & $\mathrm{R}_{2}$ & $\mathrm{R}_{3}$ & $\mathrm{X}$ \\
\hline $\mathrm{R} 1$ & $\mathrm{H}$ & $\mathrm{H}$ & $\mathrm{H}$ & $\mathrm{H}$ \\
$\mathrm{R} 2$ & $\mathrm{H}$ & $\mathrm{H}$ & $\mathrm{H}$ & $\mathrm{C}_{6} \mathrm{H}_{5}$ \\
$\mathrm{R} 3$ & $\mathrm{H}$ & $\mathrm{H}$ & $\mathrm{NO}_{2}$ & $\mathrm{H}$ \\
\hline
\end{tabular}

See Scheme 1.<smiles>[R]c1ccc(-n2c(=O)c(C(=O)OCC)cn2[X])c([R])c1[R]</smiles>

Scheme 1

proliferator-activated receptor gamma (PPARgamma) in complex with rosiglitazone (PDB entry code 1FM6) [19] was obtained from the RCSB Protein Data Bank (PDB) and utilized in order to get the detailed insights of ligandprotein structure in this study. Out of four chains in the reported protein structure $1 \mathrm{FM} 6$, only single monomer chain with rosiglitazone was selected for further work. Hydrogen atoms were added to the protein structure and were energetically optimized. Docking study was performed in single monomer by replacing rosiglitazone from reported crystal structure 1FM6. In case of docking poses showing high score, some manual adjustments were done to remove large steric hindrances and final complex structures were subjected to energy minimization using OPLS force field in Schrodinger software. During the energy minimization procedure, whole protein structure was fixed except the region within $3.5 \AA$ radius from each ligand which was relaxed.

Several pyrazole compounds have been reported for their antidiabetic effect by acting as agonist at PPARgamma [18]. Taking the guidelines of reported ligand-receptor interaction obtained from docking studies of pyrazole compounds with PPARgamma protein, the study was extended on docking study of pyrazole compounds that were reported as antidiabetic without PPARgamma agonism $[16,17]$ as shown in Tables 1 and 2 .

Rosiglitazone was removed from the complex and the reported pyrazole compounds were placed in the same cavity and were further docked in PPARgamma protein and their binding interaction was validated with previously reported binding residues [18]. These binding residues were used as reference guide. Docking was performed selectively on reported pyrazole analogues (Tables 1 and 2) for which antidiabetic activity is known to be potent and comparable to standard. This study helped in understanding possible orientations and conformation of pyrazole compounds and their resulting position and binding interaction in the pocket. Similar to the thiazolidinedione group of rosiglitazone, the carboxyl group
TABLE 2: Reported antidiabetic pyrazole-4-carboxylic acid compounds used for docking studies.

\begin{tabular}{lcc}
\hline $\begin{array}{l}\text { Reference } \\
\text { compound }\end{array}$ & $\mathrm{R}_{1}$ & $\mathrm{R}_{2}$ \\
\hline $\mathrm{R} 4$ & $\mathrm{H}$ & $\mathrm{H}$ \\
$\mathrm{R} 5$ & $\mathrm{CH}_{3}$ & $\mathrm{H}$ \\
R6 & 2-CN-[1,1'-biphenyl]-4'- $\left(\mathrm{CH}_{2}\right)$ & $\mathrm{H}$ \\
R7 & $\mathrm{CH}_{3}$ & $\left(\mathrm{CH}_{3}\right)_{2} \mathrm{C}=\mathrm{CH}-\mathrm{CH}_{2}$ \\
R8 & $\mathrm{C}_{6} \mathrm{H}_{5} \mathrm{CH}_{2}$ & $\mathrm{CH}_{3} \mathrm{CH}_{2} \mathrm{OOC}-\left(\mathrm{CH}_{2}\right)_{3}$ \\
R9 & $\mathrm{C}_{6} \mathrm{H}_{5} \mathrm{CH}_{2}$ & Tetrazole- $\mathrm{CH}_{2}$ \\
R10 & $\mathrm{H}$ & $\mathrm{CH}_{3}$ \\
\hline
\end{tabular}

See Scheme 2.<smiles>[R]Oc1nn([R1])cc1C(=O)O</smiles>

SCHEME 2

of reference compound was found to show hydrogen bonds with Tyr473 as well as Ser289 and His449. Further docking of newly designed virtual pyrazole compounds (Table 3) was performed. Docking positions with a high score were corrected manually to avoid small steric bumps, minimized energetically using OPLS force field.

2.2. G-Score. The docking studies were performed using standard precision mode of Glide. The results of the docking studies were generated in the form of G-score. The more negative value of G-score means the compound is more potent and indicates good binding potential. Besides the Gscore, other parameters like energy and E-model were also taken into consideration for the evaluation of the docking results. The values of energy and E-model were found to be significantly closer to the values of the standard rosiglitazone.

2.3. $\mathrm{H}$-Bond Interaction. As $\mathrm{H}$-bond is an influential parameter, H-bonding governs binding affinity of the docked compounds. The number of $\mathrm{H}$-bond interactions in the standard compound rosiglitazone was compared with those of the designed virtual pyrazole compounds. In case of docking of the standard compound rosiglitazone with 1FM6, only one $\mathrm{H}$-bond interaction was found.

New ligands were designed virtually to improve the binding interaction in terms of improving the hydrogen binding capability of ligand along with variation in bulkiness at ortho-, meta-, and parapositions of aromatic ring. On the basis of docking study, amino acids such as Ser342, Tyr473, and Ser289 were found to preserve binding interaction with the designed virtual molecules. The choice of best-docked structure for each ligand is made using a model energy score (E-model) that combines the energy grid score, the binding affinity predicted by GlideScore, potential energy, lipophilicity, hydrogen bond, and van der Walls energy. On 
TABLE 3: Newly designed pyrazole-3-one compounds.

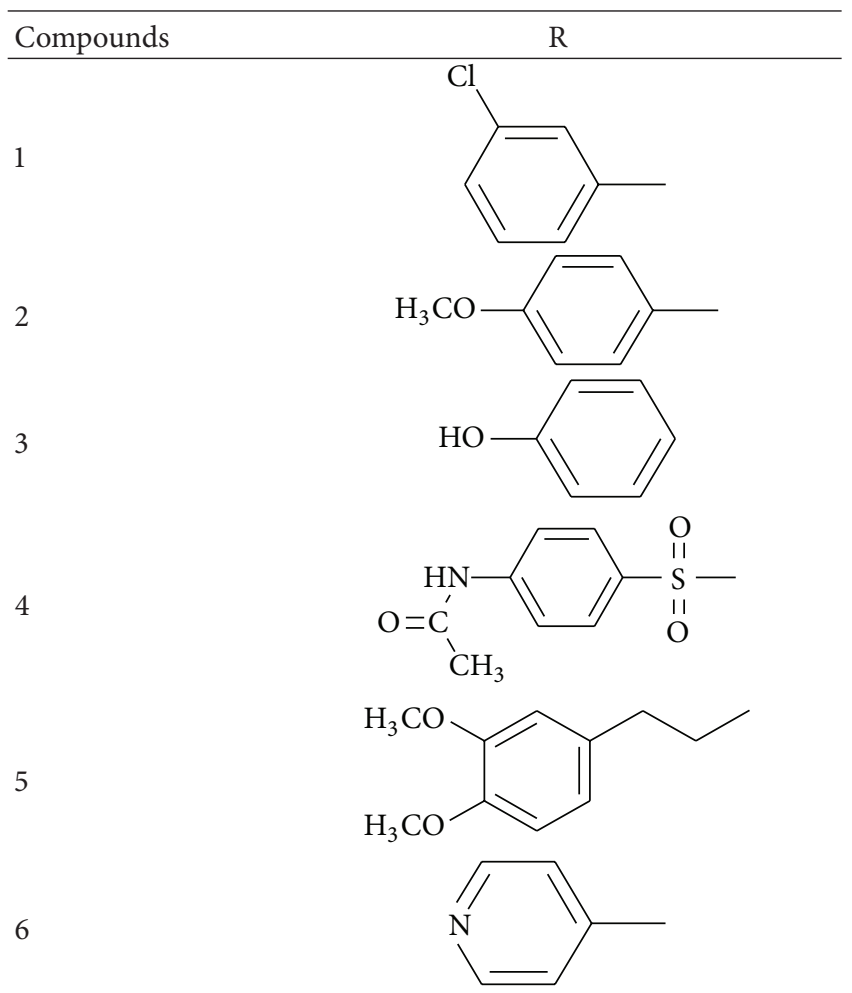

See Scheme 3.<smiles>[R]n1[nH]cc(C(=O)OCC)c1=O</smiles>

SCHEME 3

the basis of these parameters, six compounds were selected for synthesis. Table 3 shows designed virtual molecules 1, 36, while Compound 2 is reported in PubChem Compound Database (CID 20269015).

2.4. Chemistry. In light of the above, a new series of aryl substituted pyrazole-3-one derivatives were synthesized and evaluated for their possible hypoglycaemic activity. Substituted phenylhydrazines were prepared from anilines by diazotization. Pyrazole-3-one-4-carboxylate derivatives were then generated by reacting diethylethoxymethylene malonate (DEEM) with substituted phenyl hydrazine through base catalyzed cyclization reaction. The compounds were synthesized by Michael addition reaction, which is a nucleophilic addition of enolate anions to the carbon-carbon double bond of $\alpha, \beta$-unsaturated carboxylic acid derivatives. The synthesized compounds were tested for hypoglycaemic activity.
2.5. Experimental. All reagents and anhydrous solvents were generally used as they are received from the commercial supplier. Reactions were routinely performed in oven-dried glassware. Melting points were determined with Veego VMP$\mathrm{D}$ digital melting point apparatus and are uncorrected. FTIR spectra were recorded on a JASCO FTIR 4100 series spectrophotometer and are reported in $\mathrm{cm}^{-1} \cdot{ }^{1} \mathrm{H} \mathrm{NMR}$ spectra were recorded on Varian $300 \mathrm{MHz}$ in DMSO unless otherwise specified and chemical shifts are reported relative to tetramethylsilane as an internal standard.

\subsection{Scheme of Synthesis. See Figure 1.}

\subsection{General Procedure for Synthesis of Compounds 1, 3-6}

Preparation of Substituted Phenyl Hydrazine from Substituted Aniline. $5 \mathrm{~g}(0.037 \mathrm{~mol})$ of substituted amino compound was dissolved in a mixture of $10.5 \mathrm{~mL}$ of concentrated $\mathrm{HCl}$ and an equal volume of water, cooled rapidly to $0^{\circ} \mathrm{C}$ in order to obtain the hydrochloride of the base in a fine state of division. Gradual addition of a solution of $2.6 \mathrm{~g}(0.037 \mathrm{~mol})$ of sodium nitrite in $6 \mathrm{~mL}$ of water was performed for diazotization. Stirring was continued for a few minutes, and the solution was filtered and added by using a separatory funnel to an ice-cold solution made of $41 \mathrm{~g}(0.156 \mathrm{~mol})$ of sodium sulphite $\left(96 \% \mathrm{Na}_{2} \mathrm{SO}_{3} \cdot 7 \mathrm{H}_{2} \mathrm{O}\right)$ in $100 \mathrm{~mL}$ of water containing $4 \mathrm{~g}$ of $\mathrm{NaOH}$. The solution was allowed to stand for 5 minutes, acidify with $35 \mathrm{~mL}$ of concentrated $\mathrm{HCl}$, and heat on a water bath at $25^{\circ} \mathrm{C}$ for 3 minutes, when yellow needles commence separating. This solution was kept overnight, filtered off the crystals, heated with $10 \mathrm{~mL}$ of concentrated $\mathrm{HCl}$ on a water bath for 7 minutes, and allowed to cool. The precipitate was filtered off and dissolved in water and the solution was treated with a concentrated solution of sodium acetate. The free base separated out in an almost pure state [20].

\subsection{Synthesis of Aryl Substituted-1H-pyrazole- 3-one-4-carboxylate}

Procedure. Substituted phenyl hydrazine $(0.02 \mathrm{~mol})$ was dissolved in minimum amount of cold water and then ethanolic $\mathrm{KOH}$ was added. The solution was then refluxed for $40 \mathrm{~min}$ at $70^{\circ} \mathrm{C}$ in the presence of diethylethoxymethylene malonate (DEEM) $(0.02 \mathrm{~mol})$. The precipitate obtained was filtered, washed with water, and dried. The product obtained was recrystallized from ethanol and was dried for $24 \mathrm{hr}$ at room temperature and kept in a vacuum desiccator [17].

\subsection{Antidiabetic Activity}

In Vivo Studies [21]. Fasting blood glucose was determined after depriving food for $16 \mathrm{hr}$ with free access for drinking water. Initially doses of alloxan 40, 50, 65, 90, and $120 \mathrm{mg} /$ $\mathrm{kg}$ were given to six rats each and induction of diabetes was observed. Hyperglycemia was induced by a single i.p. injection of $90 \mathrm{mg} / \mathrm{kg}$ of alloxan monohydrate (Explicit Chemicals, India) in sterile saline. After 5 days of alloxan injection, 


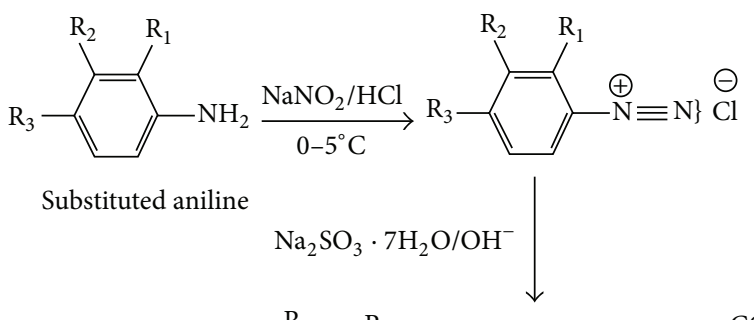<smiles>[R]COC(=O)C(=COCC)C(=O)OCC</smiles><smiles>[R3]c1ccc(-n2c(=O)c(C(=O)OCC)cn2[Tl])c([R])c1[R]</smiles>

FIGURE 1: Scheme of synthesis of pyrazole-3-one derivatives.

the hyperglycemic rats (glucose level > $200 \mathrm{mg} / \mathrm{dL}$ ) were separated and divided into different groups comprising six rats each for the antidiabetic study. The synthesized compounds were administered on 5 th day. The dose was decided on the basis of the literature. Rats in control group were given standard diet. Treatment of synthesized compound was started from the same day using 1\% CMC with the dose of $40 \mathrm{mg} / \mathrm{kg}$ (p.o.). The dose was decided as per the reported study of homologous series of pyrazole-3-one compounds [17]. Another group of six rats were given metformin as standard drug by administering dose of $120 \mathrm{mg} / \mathrm{kg}$. During this period, animals in all groups had free access to standard diet and water. The blood was withdrawn by retroorbital plexus method [22]. On the same day, the blood glucose levels were estimated by using glucometer (Johnson \& Johnson Pvt. Ltd.) with one-touch simple select strips. The blood glucose levels were estimated during $1 \mathrm{hr}, 3 \mathrm{hr}$, and $6 \mathrm{hr}$. Out of 48 rats, 45 rats survived. The dead rats were disposed of as per standard protocol of CPCSEA rules.

\section{Results}

3.1. Molecular Docking Study of Pyrazole Compounds. Initially docking of rosiglitazone was validated with docking studies. Binding behavior of reported antidiabetic pyrazole compounds was studied due to their structural difference from thiazolidinedione. Number of hydrogen binding ability of pyrazole derivatives was different from thiazolidinediones and hence comparison between two different scaffolds was not possible in terms of hydrogen-bonding interaction. Only common residues can be identified.

Docking results of reported pyrazole molecules and their binding interactions with residues within $3 \AA$ radius were found out to understand the specific type of binding interactions of molecular features of pyrazole compounds $[16,17]$. G-score value obtained after docking study was compared with antidiabetic activity of each of reported reference pyrazole compounds. G-score of potent pyrazoles was found to be correlated. Thereby crucial residues of binding interaction among the potent reported pyrazole compounds were identified. The presence or absence of these crucial residues was observed in docking study of novel pyrazole-3one compounds $1,3-6$.

Figures 2, 3, 4, 5, 6, and 7 show the docked compounds $(1,3,4,5$, and 6 , rosiglitazone) in the active site of 1FM6, respectively. The ligands are shown colored in atom type with ball and stick representation.

Table 4 shows results of docking of reported pyrazole-3one molecules showing hydrogen-bonding interaction with Ser289, Ser342, and Glu343. Table 5 shows results of docking 


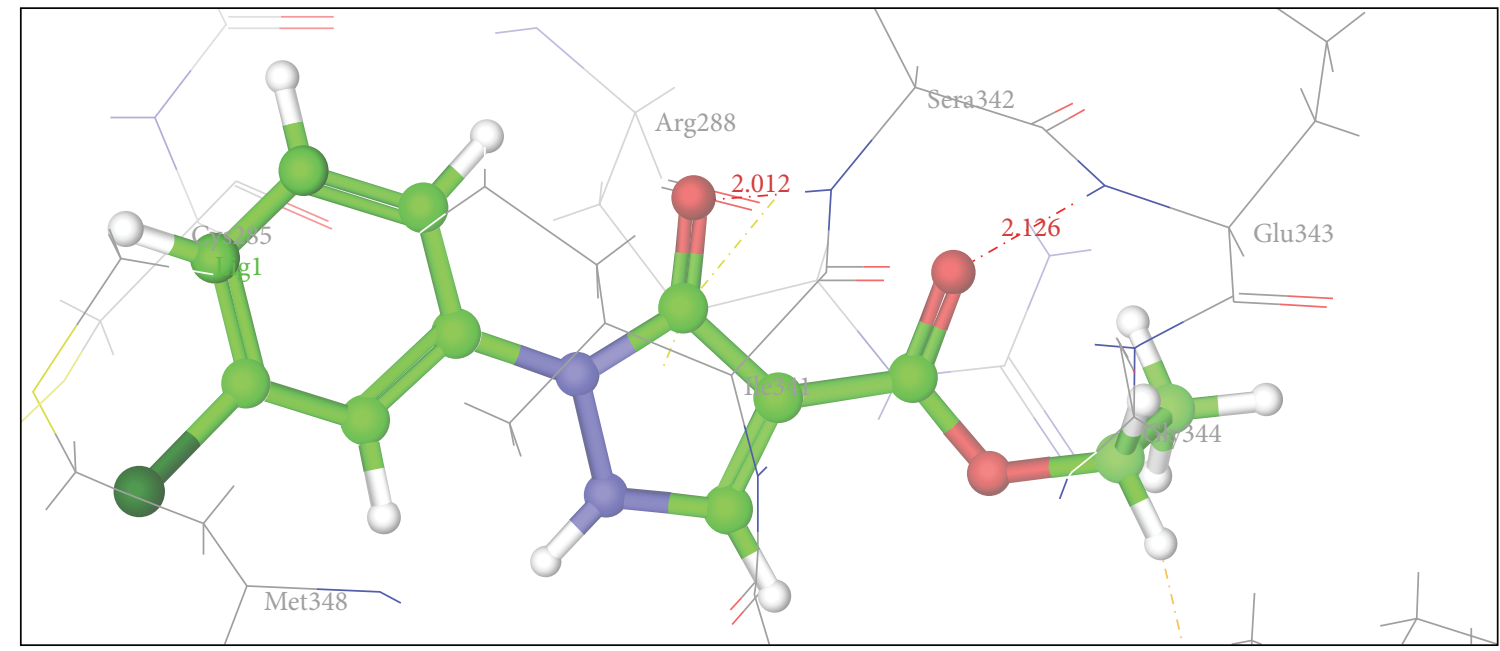

FIGURE 2: Docking pose of Compound 1 having interaction with Ser342 and Glu343.

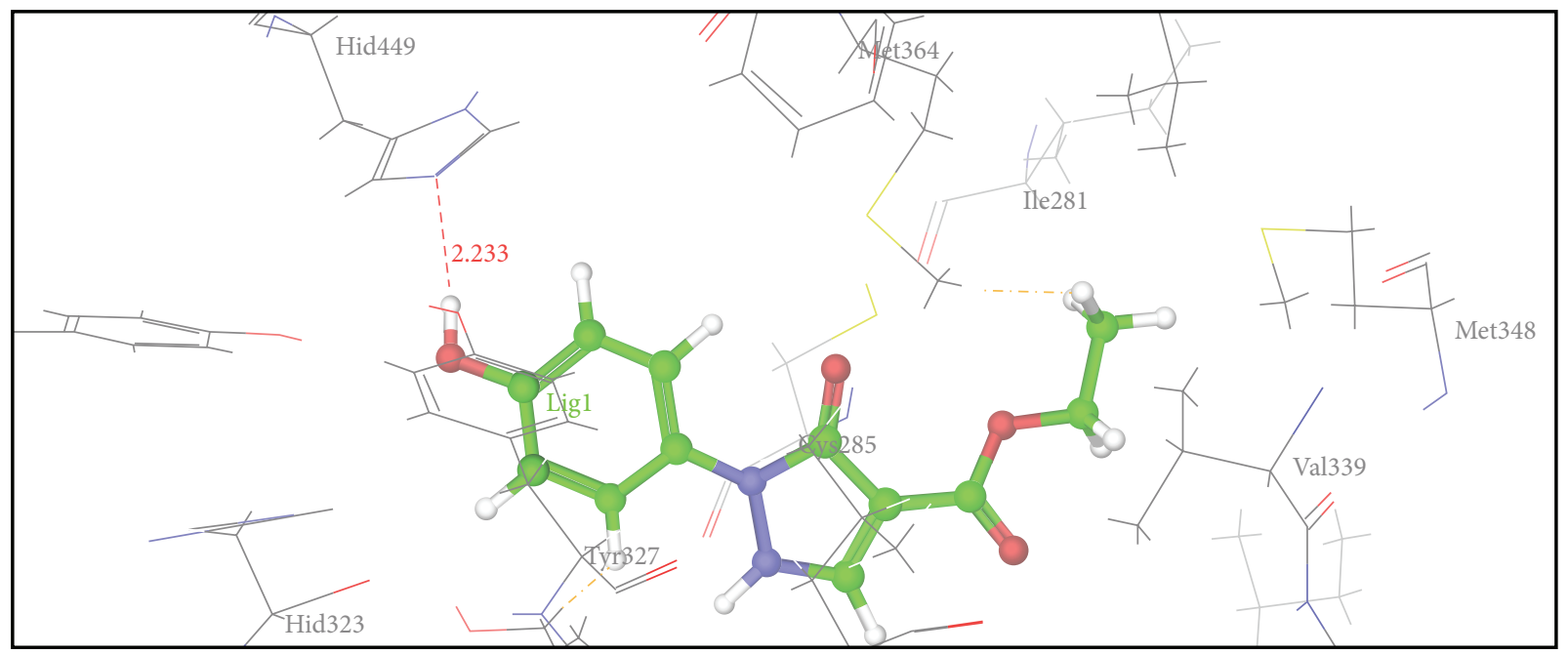

FIGURE 3: Docking pose of Compound 3 having interaction with His449.

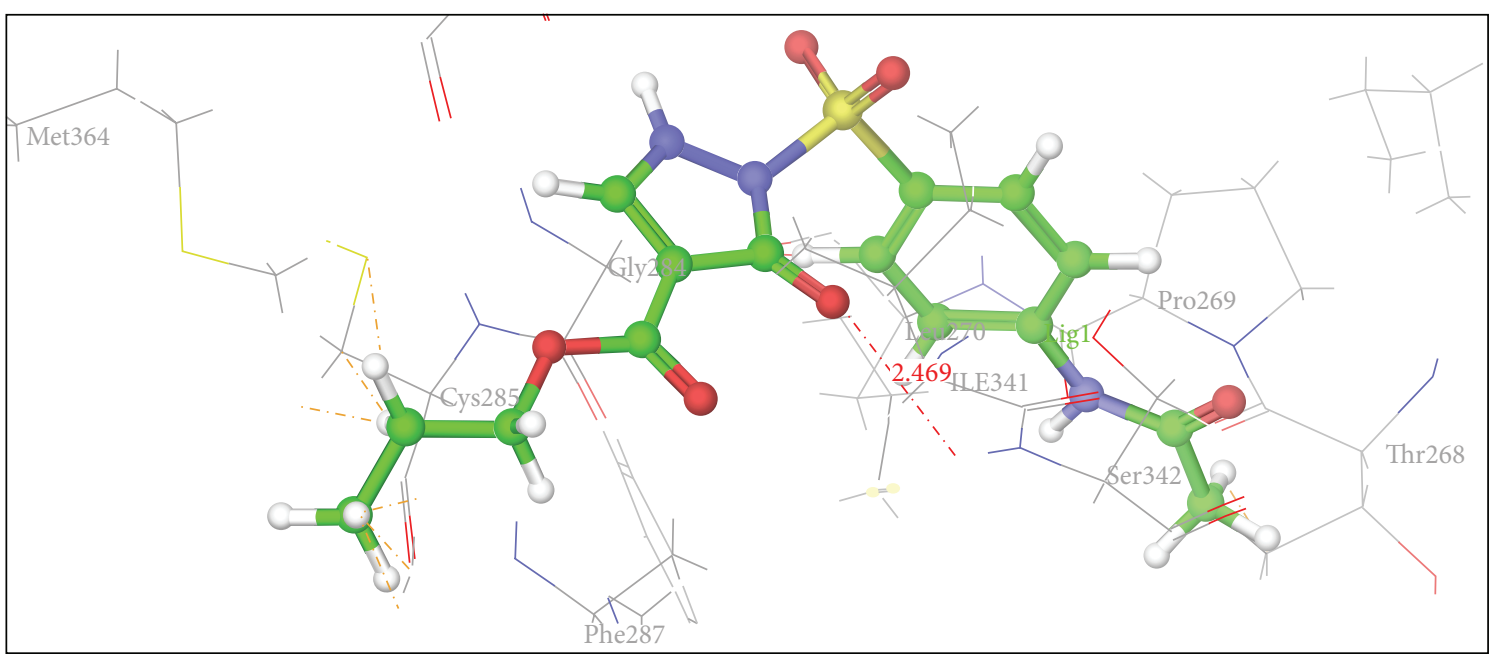

FIgURE 4: Docking pose of Compound 4 having interaction with Ser342. 


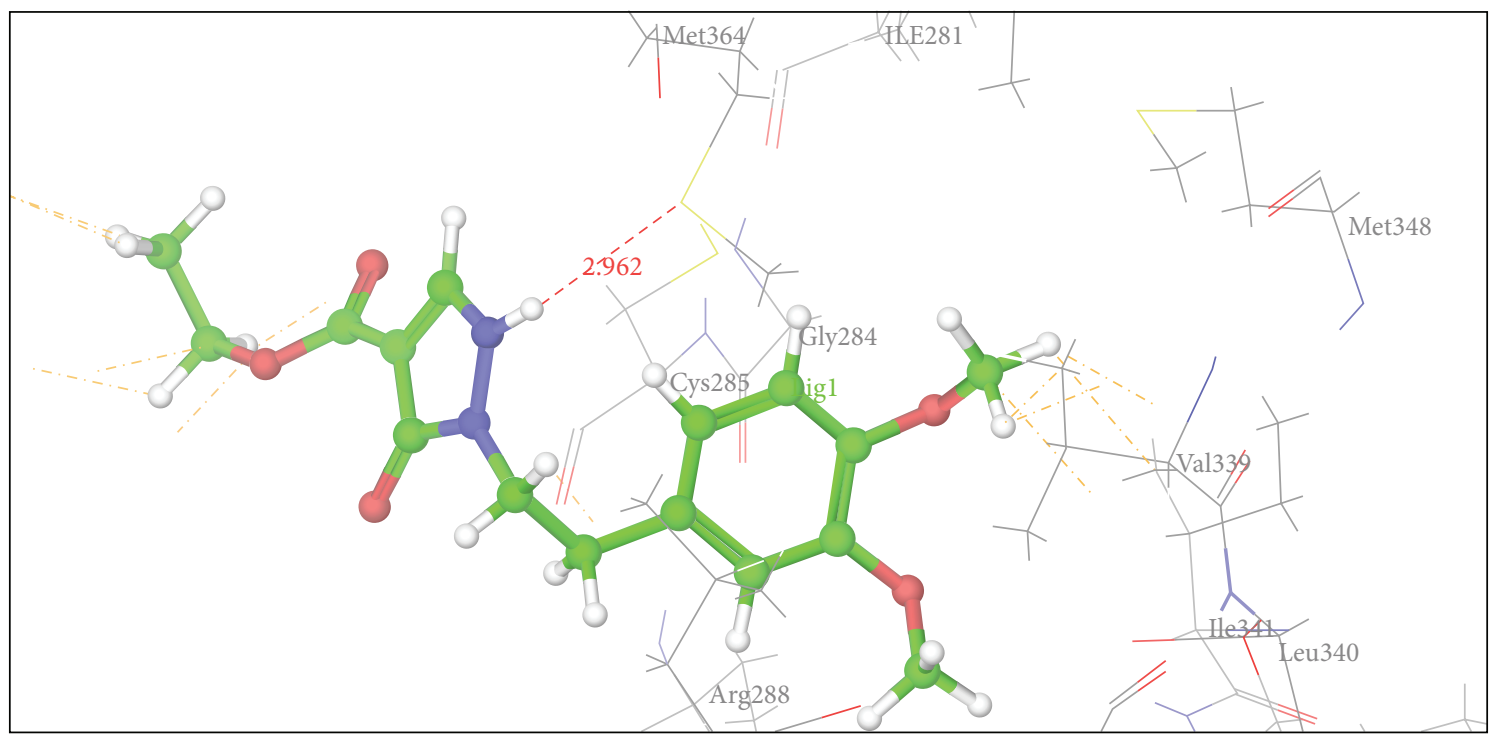

FIGURE 5: Docking pose of Compound 5 having interaction with Met364.

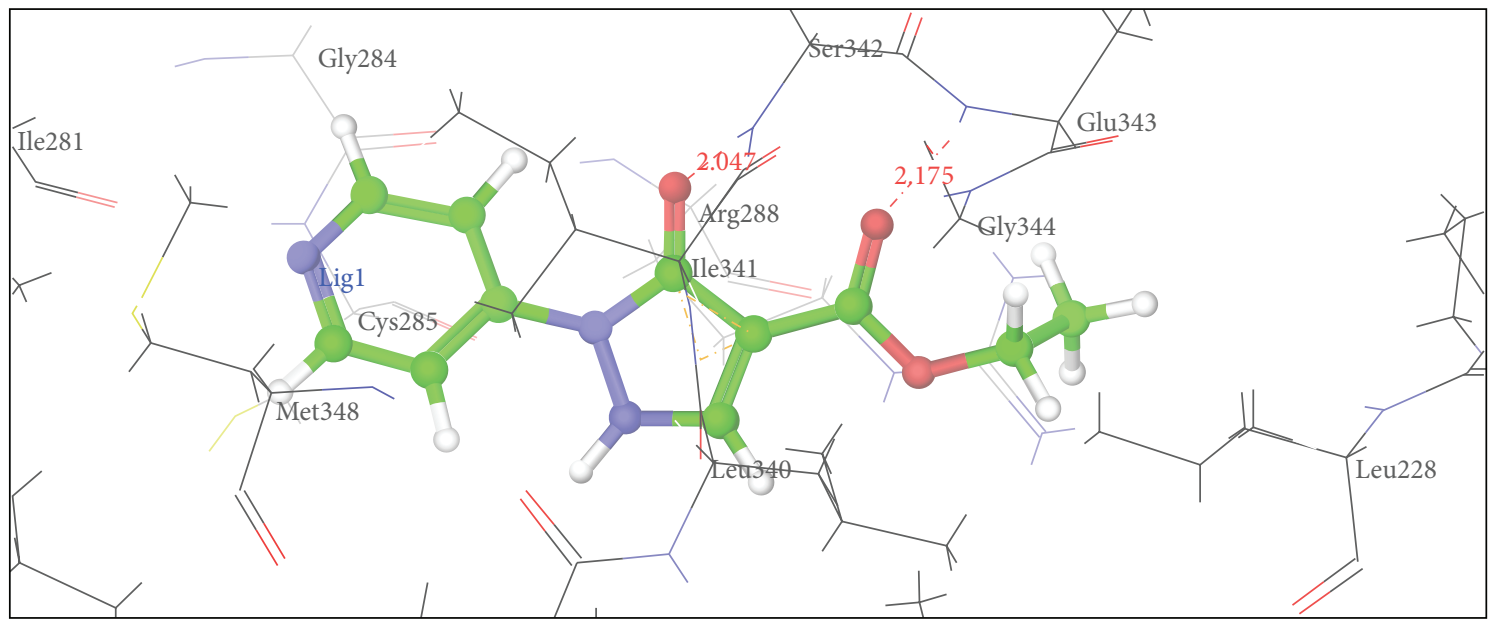

FIGURE 6: Docking pose of Compound 6 having interaction with Ser342 and Glu343.

of reported carboxylate anion of pyrazole-4-carboxylic acid derivatives that act as an anchor to bind to the amino acid residues such as Ser289, Ser342, and Tyr473. Thus, Tables 4 and 5 show common residues such as Ser342 and Ser289. From these results, it was observed that both the reported pyrazole compounds have common binding interaction with Ser289 as that of rosiglitazone. Table 6 shows amino acid interactions within $3 \AA$ distance for each designed compound $(1,3-6)$. This region of binding is similar to binding region of rosiglitazone except for Compound 2, which drifts away from this region.

By considering the docking parameters such as docking score, electrostatic coulomb, and van der Waals energy parameters potency of the compounds was estimated.

In comparison to position of rosiglitazone, in the docking model of the literature based Compound 2 (CID 20269015), the pyrazole ring slightly shifts away due to binding interaction of $-\mathrm{OCH}_{3}$ group at His 449. Similarly in case of designed
Compound 3 presence of phenolic $\mathrm{OH}$ group at $\mathrm{R}$ position fell to reach the important binding interaction. Compound 5 shows large number of bad van der Waals contacts resembling the strained binding interaction with His449 due to two methoxy substituents on aromatic ring at R. In Compound 6 , presence of pyridine ring at $\mathrm{R}$ shifts away the molecule leading to nonbonding attraction of electronegative $\mathrm{N}$ atom. Compound 1 showed close anchoring of carboxylate ion with the Glu343 and Ser342 residues. This anchoring is very similar to the binding interaction observed in pyrazole-4carboxylic acid reference structures as well as propionic acid derivatives reported in crystal structure. In Compound 4, introduction of 4-acetamidobenzenesulphonamide was expected to form increase in one or two hydrogen bonds. As shown in Figure 3, 4-acetamidobenzenesulphonamide group exhibited hydrogen bond with Ser342 via the carbonyl oxygen of pyrazole-3-one ring. The docking study of Compound 4 showed hydrogen bonding with carbonyl group of 


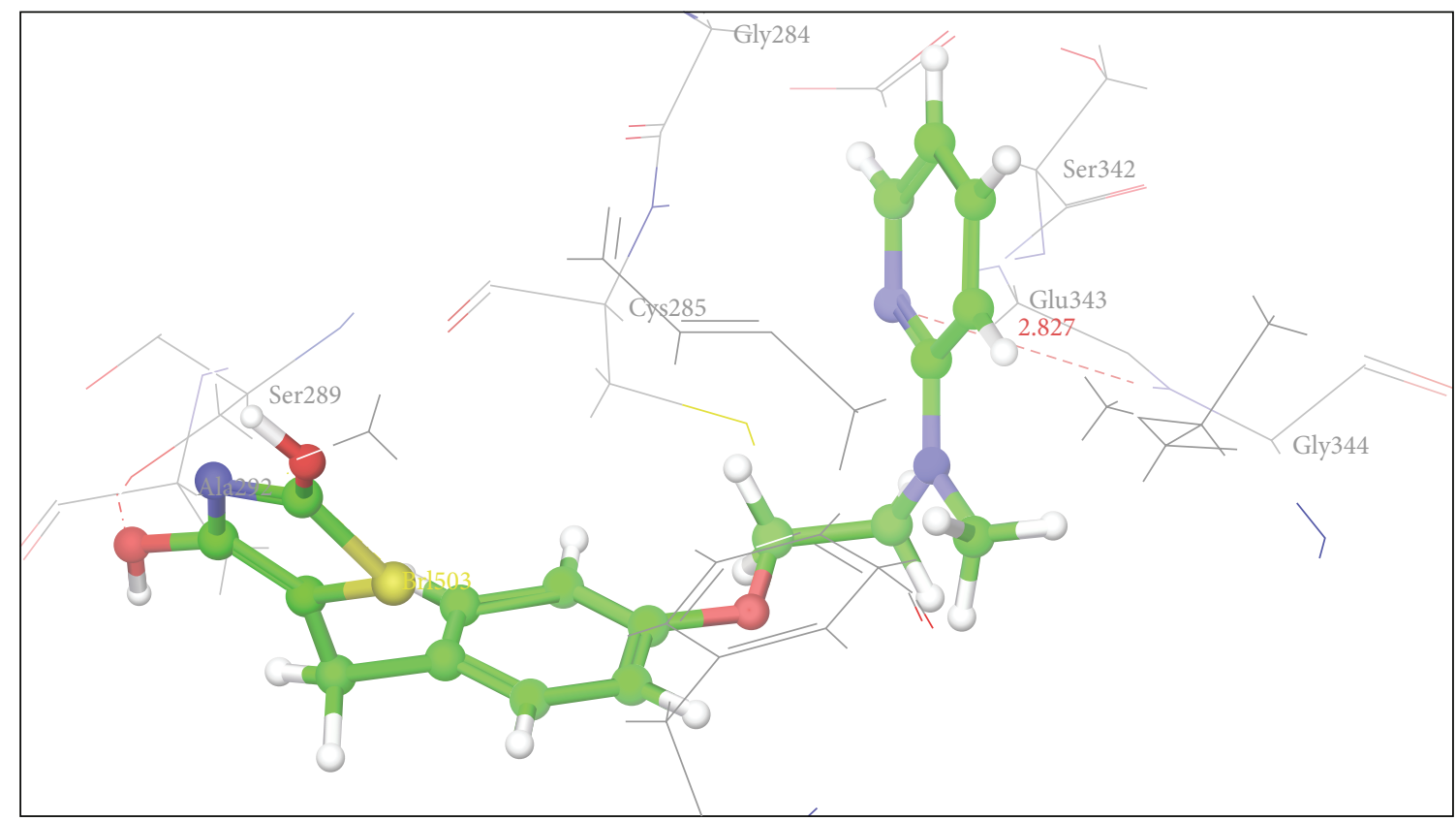

FIGURE 7: Docking pose of rosiglitazone having interaction with Ser342 and Ser289.

TABLE 4: Results of docking studies for reported pyrazole-3-one molecules and their binding interactions with residues within $3 \AA$ radius.

\begin{tabular}{lccccc}
\hline $\begin{array}{l}\text { Reference } \\
\text { compound }\end{array}$ & $\begin{array}{c}\text { Number of } \\
\text { hydrogen bonds }\end{array}$ & $\begin{array}{c}\text { Hydrogen } \\
\text { bond distance }\end{array}$ & $\begin{array}{c}\text { Group of } \\
\text { compounds }\end{array}$ & $\begin{array}{c}\text { Group of } \\
\text { amino acids }\end{array}$ & $\begin{array}{c}\text { Residue } \\
\text { number }\end{array}$ \\
\hline R1 & 2 & 2.022 & $-\mathrm{C}=\mathrm{O}$ & $-\mathrm{NH}$ & Ser342 \\
& & 2.094 & $-\mathrm{C}=\mathrm{O}$ & $-\mathrm{NH}$ & $\mathrm{Glu}$ \\
R2 & 1 & 2.470 & $-\mathrm{C}=\mathrm{O}$ & $-\mathrm{NH}$ & Ser342 \\
R3 & 2 & 1.982 & $-\mathrm{C}=\mathrm{O}$ & $-\mathrm{NH}$ & Ser342 \\
& & 2.066 & $-\mathrm{C}=\mathrm{O}$ & $-\mathrm{NH}$ & $\mathrm{Glu} 343$ \\
\hline
\end{tabular}

pyrazole-3-one due to particular orientation and flexibility of 4-acetamidobenzenesulphonamide group which might have made carbonyl group of pyrazole-3-one accessible for crucial binding. This interaction is absent in all other compounds. These docking results suggest that the pyrazole substituted 4acetamidobenzenesulphonamides are a new class of selective PPARgamma agonists. Table 7 shows hydrogen bonding of the designed molecules with amino acid residue.

\subsection{Characterization of Synthesized Compounds}

(1) Compound 1. Yield: 32.45\%; m.p. $260-261^{\circ} \mathrm{C}$; Rf value (0.53), IR(KBr): 3288.04 (NH str), 1706.69 (-CO str of ester), 1679.68 ( $-\mathrm{C}=\mathrm{O}), 1590.99$ (Ar-C-C-str), 752.10 $(\mathrm{Cl}) ;{ }^{1} \mathrm{H}$ NMR (DMSO): $\delta 2.5\left(\mathrm{~s}, 3 \mathrm{H},-\mathrm{CH}_{3}\right), 4.0(\mathrm{q}$, $2 \mathrm{H},-\mathrm{OCH}_{2}$ ), 7.6-8.0 (m, 4H, Ar-H), $8.6(\mathrm{~s}, 1 \mathrm{H},-\mathrm{NH})$.

(2) Compound 3. Yield: $17.17 \%$; m.p. $103-104^{\circ} \mathrm{C}$; Rf value (0.87), IR(KBr): 3517.52 (-OH), 3460.63 (NH str.), 1772.25 (-CO str of ester), $1606.45(-\mathrm{C}=\mathrm{O}) ;{ }^{1} \mathrm{H}$ NMR (DMSO): $\delta 2.46\left(\mathrm{~s}, 3 \mathrm{H},-\mathrm{CH}_{3}\right), 3.9\left(\mathrm{q}, 2 \mathrm{H},-\mathrm{OCH}_{2}\right)$, 5.2 (s, 1H, -OH), 7.72 (m, 4H, Ar-H), 8.5 (s, 1H, -NH).
(3) Compound 4. Yield: $29.46 \%$; m.p. $167-168^{\circ} \mathrm{C}$, Rf value (0.84), IR(KBr): 3370 ( $\mathrm{NH}$ str.), 1658.48 (-C=O), 1594.84 (Ar-C-C-Str.), 1260.25 (-NH amide), 1037.52 (-S-); ${ }^{1} \mathrm{H}$ NMR (DMSO): $\delta 2.45\left(\mathrm{~s}, 6 \mathrm{H},-\mathrm{CH}_{3}\right), 4.2$ $\left(\mathrm{q}, 2 \mathrm{H},-\mathrm{OCH}_{2}\right), 6.8(\mathrm{~m}, 2 \mathrm{H}, \mathrm{Ar}-\mathrm{H}), 7.2$ (m, 2H, Ar$\mathrm{H}), 8.5$ (s, 1H, -NH), 10.6 (s, 1H, -CONH).

(4) Compound 5. Yield: 37.87\%; Semisolid, Rf value (0.59), IR(KBr): 3328.53 (NH str.), 1742.37 ( $\mathrm{C}=\mathrm{O}$ ester), 1702.84 ( $-\mathrm{C}=\mathrm{O}), 1529.27$ (Ar-C-C-Str.), 1213.97 (-CO ether); ${ }^{1} \mathrm{H}$ NMR (DMSO): $\delta 2.6\left(\mathrm{t}, 3 \mathrm{H},-\mathrm{CH}_{3}\right), 3.5$ $\left(4 \mathrm{H}, \mathrm{m},-\mathrm{CH}_{2}\right), 3.9\left(\mathrm{~s}, 6 \mathrm{H},-\mathrm{OCH}_{3}\right), 4.20(\mathrm{q}, 2 \mathrm{H},-$ $\mathrm{OCH}_{2}$ ), 6.65-7.2 (m, 4H, Ar-H), 9.25 (s, 1H, -NH).

(5) Compound 6. Yield: 16.77\%, Semisolid, Rf value (0.49), IR(KBr): 3361 (NH str.), 1746 (C=O ester), 1711 $(-\mathrm{C}=\mathrm{O}), 1304(\mathrm{CN}) ;{ }^{1} \mathrm{H}$ NMR (DMSO): $\delta 2.45(\mathrm{t}, 3 \mathrm{H}$, $\left.-\mathrm{CH}_{3}\right), 4.19\left(\mathrm{q}, 2 \mathrm{H},-\mathrm{OCH}_{2}\right), 8.4(\mathrm{~m}, 4 \mathrm{H}$, pyridine), $9.2(\mathrm{~s}, 1 \mathrm{H},-\mathrm{NH})$.

3.3. Antidiabetic Activity: In Vivo Studies. Table 8 shows blood glucose level which is expressed in $\mathrm{mg} / \mathrm{dL}$ where Compounds 1 and 4 showed more potency. 
TABLE 5: Results of docking studies for reported pyrazole-4-carboxylic acid molecules and their binding interactions with residues within $3 \AA$ radius.

\begin{tabular}{|c|c|c|c|c|c|}
\hline $\begin{array}{l}\text { Reference } \\
\text { compound }\end{array}$ & $\begin{array}{c}\text { Number of } \\
\text { hydrogen bonds }\end{array}$ & $\begin{array}{l}\text { Hydrogen bond } \\
\text { distance }\end{array}$ & $\begin{array}{l}\text { Functional group } \\
\text { of compounds }\end{array}$ & $\begin{array}{l}\text { Functional group } \\
\text { of amino acids }\end{array}$ & $\begin{array}{l}\text { Residue } \\
\text { number }\end{array}$ \\
\hline $\mathrm{R} 4$ & 1 & 2.280 & $-\mathrm{N}$ & $-\mathrm{OH}$ & Ser289 \\
\hline R5 & 1 & 2.639 & $-\mathrm{C}=\mathrm{O}$ & $-\mathrm{OH}$ & Ser289 \\
\hline R6 & 1 & 2.659 & $-\mathrm{CN}$ & $-\mathrm{NH}$ & Ser342 \\
\hline R7 & 1 & 2.138 & $-\mathrm{O}-\mathrm{CH}_{3}$ & $-\mathrm{OH}$ & Tyr473 \\
\hline $\mathrm{R} 8$ & 1 & 2.824 & $-\mathrm{OH}$ & $-\mathrm{C}=\mathrm{O}$ & Leu340 \\
\hline \multirow{2}{*}{ R9 } & \multirow{2}{*}{2} & 2.606 & $-\mathrm{OH}$ & $-\mathrm{O}-\mathrm{C}=\mathrm{O}$ & Glu291 \\
\hline & & 2.067 & $-\mathrm{NH}$ & $-\mathrm{C}=\mathrm{O}$ & $\mathrm{G} \ln 271$ \\
\hline $\mathrm{R} 10$ & 1 & 2.324 & $-\mathrm{C}=\mathrm{O}$ & $-\mathrm{OH}$ & Ser289 \\
\hline
\end{tabular}

TABLE 6: Amino acid interactions within 3 Å distance from the compound.

\begin{tabular}{|c|c|c|c|c|c|c|c|}
\hline Compound & & & & acid inte & & & \\
\hline 1 & Ser 342 & Glu 343 & Gly 344 & Arg 288 & Cys 285 & Met 348 & Ile 341 \\
\hline 1 & * & * & - & - & - & - & - \\
\hline 3 & His 449 & Tyr 327 & Cys 285 & Ile 281 & Val 339 & Met 348 & His 323 \\
\hline & $*$ & - & - & - & - & - & - \\
\hline 4 & Pro 269 & Ser 342 & Thr 268 & Gly 264 & Cys 285 & Phe 287 & Leu 270 \\
\hline & - & * & - & - & - & - & - \\
\hline 5 & Met 288 & Ile 281 & Cys 285 & Gly 284 & Arg 288 & Val 339 & Leu 340 \\
\hline & $*$ & - & - & - & - & - & - \\
\hline 6 & Ser 342 & Glu 343 & Gly 344 & Leu 340 & Cys 285 & Gly 284 & Met 348 \\
\hline & $*$ & $*$ & - & - & - & - & - \\
\hline Rosiolitazone & Glu 343 & Ser 342 & Cys 285 & Gly 284 & Ser 289 & Gly 344 & Ala 292 \\
\hline & - & $*$ & - & - & $*$ & - & - \\
\hline
\end{tabular}

- means absence of interaction; * means interaction.

TABLE 7: H-bonding interactions and G-score results of docking studies of designed molecules.

\begin{tabular}{|c|c|c|c|c|}
\hline \multirow{2}{*}{ Compound } & \multicolumn{2}{|c|}{ H-bond } & \multirow{2}{*}{$\begin{array}{l}\text { Number of } \\
\text { H-bonds }\end{array}$} & \multirow{2}{*}{ G-score } \\
\hline & Amino acid & Distance $(\AA)$ & & \\
\hline \multirow{2}{*}{1} & Ser342 & 2.019 & & \multirow{2}{*}{-8.04} \\
\hline & Glu343 & 2.126 & 2 & \\
\hline 3 & His446 & 2.233 & 1 & -7.23 \\
\hline 4 & Ser342 & 2.489 & 1 & -7.29 \\
\hline 5 & Met364 & 2.962 & 1 & -8.02 \\
\hline \multirow{2}{*}{6} & Ser342 & 2.047 & & \multirow{2}{*}{-7.25} \\
\hline & Glu343 & 2.175 & 2 & \\
\hline Rosiglitazone & Ser342 & 2.827 & 1 & -9.94 \\
\hline
\end{tabular}

In Figure 8, the graph that expresses blood glucose level for intervals of 1,3 , and $6 \mathrm{hr}$ and data was analyzed by Bonferroni post hoc test, using two-way ANOVA method [21].

\section{Discussion}

The results of the docking studies are presented in the form of G-score. The G-scores are presented as negative values,
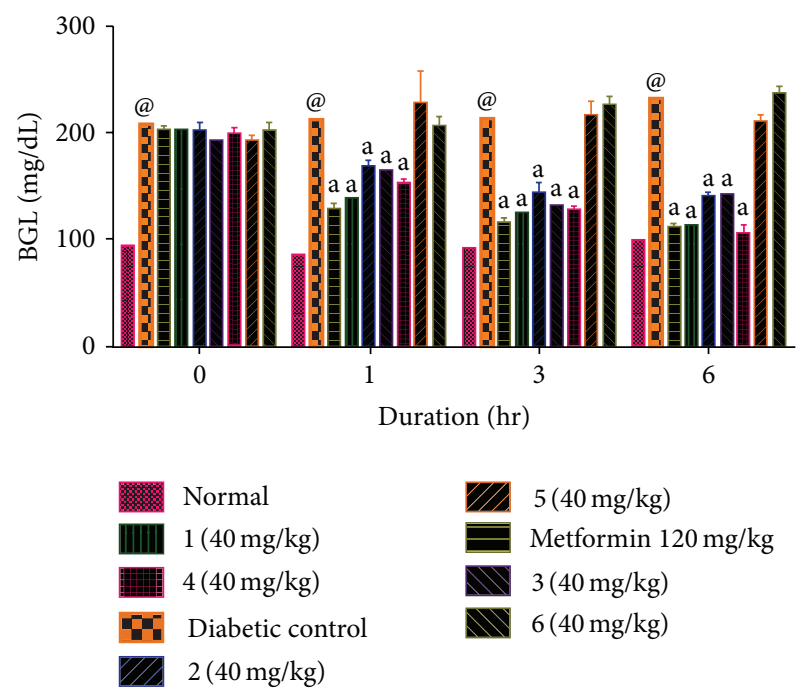

Figure 8: Effect of metformin $120 \mathrm{mg} / \mathrm{kg}$ p.o. and 1, 2, 3, 4, 5, and $6(40 \mathrm{mg} / \mathrm{kg}$, p.o.) on blood glucose level. Values in parentheses indicate the dose in $\mathrm{mg} / \mathrm{kg}$. Data are expressed as mean \pm SEM and analyzed by Bonferroni post hoc test, using two-way ANOVA, $n=6$ rats per group; ${ }^{\mathrm{a}} P<0.001$, as compared to diabetic control, and ${ }^{\circledR} P<0.001$ as compared to normal. 
TABLE 8: Biological evaluation of compounds on Wistar rats.

\begin{tabular}{lcccc}
\hline Drug & \multicolumn{4}{c}{ Blood glucose level mg/dL (mean \pm SE) } \\
& $0 \mathrm{hr}$ & $1 \mathrm{hr}$ & $3 \mathrm{hr}$ & $6 \mathrm{hr}$ \\
\hline Normal & $90.667 \pm 1.585$ & $90.667 \pm 1.585$ & $92.00 \pm 1.438$ & $91.500 \pm 1.996$ \\
1 & $201.333 \pm 4.379$ & $137.333 \pm 2.963$ & $123.667 \pm 3.461$ & $112.833 \pm 4.909$ \\
2 (CID 20269015) & $201.833 \pm 4.778$ & $167.833 \pm 3.468$ & $151.00 \pm 2.098$ & $139.833 \pm 2.358$ \\
3 & $198.333 \pm 9.584$ & $155.167 \pm 3.321$ & $136.833 \pm 2.197$ & $125.00 \pm 4.139$ \\
4 & $198.667 \pm 2.629$ & $151.500 \pm 1.648$ & $125.833 \pm 1.887$ & $107.333 \pm 3.658$ \\
5 & $190.00 \pm 5.471$ & $226.667 \pm 28.273$ & $215.167 \pm 10.150$ & $210.00 \pm 3.873$ \\
6 & $200.00 \pm 7.038$ & $204.667 \pm 7.292$ & $225.333 \pm 5.719$ & $235.833 \pm 4.527$ \\
Diabetic control & $206.167 \pm 5.747$ & $210.667 \pm 4.364$ & $212.00 \pm 4.494$ & $229.667 \pm 5.942$ \\
Metformin & $201.167 \pm 2.120$ & $127.333 \pm 3.621$ & $114.833 \pm 3.219$ & $110.500 \pm 1.607$ \\
\hline
\end{tabular}

indicating that higher negative values resemble higher binding interaction. The docking studies were performed for the designed pyrazoles (as shown in Table 7) with PPARgamma enzyme, and the results were compared with rosiglitazone and reported pyrazole compounds present within the receptor. The docked complexes of the designed compounds along with the ligand receptor poses showed ligand occupying similar binding pocket as that of rosiglitazone although differed in their binding to different amino acid residues. The designed compounds were found to display good binding affinity to the receptor in terms of hydrogen binding and Gscore values. Red dotted lines in Figures 2 to 7 indicate $\mathrm{H}$ bond interactions with receptor. In vivo studies of alloxan induced diabetes rat model show that Compounds 1 and 4 have more potency while Compounds 2 (CID 20269015) and 3 have moderate potency compared to standard. Compounds 5 and 6 were least active. The results were calculated by measuring the mean \pm SEM " $P$ " value and analyzed by Bonferroni post hoc test, using two-way ANOVA (Graph pad, prism software version 4.03, USA).

On the basis of docking results, Compound 1 was having more potency than Compound 4, but according to in vivo study, we found that Compound 4 has more potency over Compound 1. This small difference in potency of Compounds 1 and 4 was not expressed in terms of G-score. As per docking results, Compounds 2, 3, 5, and 6 showed poor binding affinity which has been reflected in the in vivo study. Thus, results were matching with actual experimental studies.

\section{Conclusion}

The pyrazole compounds were designed to have antidiabetic activity using docking studies. Docking study has revealed crucial hydrogen binding of carbonyl oxygen of pyrazole3-one compounds. Docking studies have also helped in reducing synthetic work thereby saving time and chemical expenditure. Experimental in vivo study results matched with docking study. On the basis of docking studies using PPARgamma protein, we cannot claim the above compounds to be active for PPARgamma but they are antidiabetic based on in vivo experimental studies.

\section{Conflict of Interests}

The authors declare that there is no conflict of interests regarding the publication of this paper.

\section{Acknowledgments}

The authors would like to thank Prasad Kute and Umesh Mahajan for their help in activity studies.

\section{References}

[1] M. T. Malecki and T. Klupa, "Type 2 diabetes mellitus: from genes to disease," Pharmacological Reports, vol. 57, supplement, pp. 20-32, 2005.

[2] J. B. Buse, D. C. Klonoff, L. L. Nielsen et al., "Metabolic effects of two years of exenatide treatment on diabetes, obesity, and hepatic biomarkers in patients with type 2 diabetes: an interim analysis of data from the open-label, uncontrolled extension of three double-blind, placebo-controlled trials," Clinical Therapeutics, vol. 29, no. 1, pp. 139-153, 2007.

[3] V. M. Altan, "The pharmacology of diabetic complications," Current Medicinal Chemistry, vol. 10, no. 15, pp. 1317-1327, 2003.

[4] S. Wild, G. Roglic, A. Green, R. Sicree, and H. King, "Global prevalence of diabetes: estimates for the year 2000 and projections for 2030," Diabetes Care, vol. 27, no. 5, pp. 1047-1053, 2004.

[5] E. Adeghate, "Medicinal chemistry of novel anti-diabetic drugs," The Open Medicinal Chemistry Journal, vol. 5, no. 2, pp. 68-69, 2011.

[6] P. D. Gokulan, B. Jayakar, V. Alagarsamy, and S. V. Raja, "Synthesis and pharmacological investigation of 5-substituted3-methylsulfanyl-1H-pyrazole-4-carboxylic acid ethyl esters as new analgesic and anti-inflammatory agents," Arzneimittelforschung, vol. 62, no. 10, pp. 457-462, 2012.

[7] S. B. Yewale, S. B. Ganorkar, K. G. Baheti, and R. U. Shelke, "Novel 3-substituted-1-aryl-5-phenyl-6-anilinopyrazolo[3,4d]pyrimidin-4- ones: docking, synthesis and pharmacological evaluation as a potential anti-inflammatory agents," Bioorganic and Medicinal Chemistry Letters, vol. 22, no. 21, pp. 6616-6620, 2012.

[8] H. M. Faidallah, K. A. Khan, and A. M. Asiri, "Synthesis and biological evaluation of new 3-trifluoromethylpyrazolesulfonylurea and thiourea derivatives as antidiabetic and antimicrobial 
agents," Journal of Fluorine Chemistry, vol. 132, no. 2, pp. 131-137, 2011.

[9] M. Abdel-Aziz, G. A. Abuo-Rahma, and A. A. Hassan, "Synthesis of novel pyrazole derivatives and evaluation of their antidepressant and anticonvulsant activities," European Journal of Medicinal Chemistry, vol. 44, no. 9, pp. 3480-3487, 2009.

[10] A. M. Vijesh, A. M. Isloor, P. Shetty, S. Sundershan, and H. K. Fun, "New pyrazole derivatives containing 1,2,4-triazoles and benzoxazoles as potent antimicrobial and analgesic agents," European Journal of Medicinal Chemistry, vol. 62, pp. 410-415, 2013.

[11] M. M. Alam, A. Marella, M. Akhtar et al., "Microwave assisted one pot synthesis of some pyrazole derivatives as a safer anti-inflammatory and analgesic agents," Acta Poloniae Pharmaceutica-Drug Research, vol. 70, no. 3, pp. 435-441, 2013.

[12] O. I. El-Sabbagh, M. Baraka, S. Ibrahim et al., "Synthesis and antiviral activity of new pyrazole and thiazole derivatives," European Journal of Medicinal Chemistry, vol. 44, no. 9, pp. 3746-3753, 2009.

[13] X. Li, X. Lu, M. Xing et al., "Synthesis, biological evaluation, and molecular docking studies of N,1,3-triphenyl-1H-pyrazole4-carboxamide derivatives as anticancer agents," Bioorganic and Medicinal Chemistry Letters, vol. 22, no. 11, pp. 3589-3593, 2012.

[14] M. J. Genin, C. Biles, B. J. Keiser et al., "Novel 1,5-diphenylpyrazole nonnucleoside HIV-1 reverse transcriptase inhibitors with enhanced activity versus the delavirdine-resistant P236L mutant: lead identification and SAR of 3- and 4-substituted derivatives," Journal of Medicinal Chemistry, vol. 43, no. 5, pp. 1034-1040, 2000.

[15] K. Kees, J. Fitzgerald, K. Steiner, and J. Matter, "New potent antihyperglycemic agents in $\mathrm{db} / \mathrm{db}$ mice: synthesis and atructure-activity relationship studies of (4-Substituted benzyl)(trifluoromethyl)pyrazoles and -pyrazolones," Journal of Medicinal Chemistry, vol. 39, no. 20, pp. 3920-3928, 1996.

[16] B. Cottineau, P. Toto, C. Marot, A. Pipaud, and J. Chenault, "Synthesis and hypoglycemic evaluation of substituted pyrazole-4carboxylic acids," Bioorganic and Medicinal Chemistry Letters, vol. 12, no. 16, pp. 2105-2108, 2002.

[17] N. Das, A. Verma, P. K. Shrivastava, and S. K. Shrivastava, "Synthesis and biological evaluation of some new aryl pyrazol3-one derivatives as potential hypoglycemic agents," Indian Journal of Chemistry Section B, vol. 47, no. 10, pp. 1555-1558, 2008.

[18] K. Rikimaru, T. Wakabayashi, H. Abe et al., "A new class of nonthiazolidinedione, non-carboxylic-acid-based highly selective peroxisome proliferator-activated receptor (PPAR) $\gamma$ agonists: design and synthesis of benzylpyrazole acylsulfonamides," Bioorganic and Medicinal Chemistry, vol. 20, no. 2, pp. 714-733, 2012.

[19] R. T. Gampe Jr., V. G. Montana, M. H. Lambert et al., "Asymmetry in the PPAR $\gamma / \mathrm{RXR} \alpha$ crystal structure reveals the molecular basis of heterodimerization among nuclear receptors," Molecular Cell, vol. 5, no. 3, pp. 545-555, 2000.

[20] B. S. Furnis, A. J. Hannaford, P. W. G. Smith, and A. R. Tatchell, Vogel's Textbook of Practical Organic Chemistry, Pearson Education, Essex, UK, 5th edition, 2005.

[21] H. van Herck, V. Baumans, C. J. W. M. Brandt et al., "Blood sampling from the retro-orbital plexus, the saphenous vein and the tail vein in rats: comparative effects on selected behavioural and blood variables," Laboratory Animals, vol. 35, no. 2, pp. 131139, 2001.
[22] O. Akinola, M. Gabriel, A.-A. Suleiman, and F. Olorunsogbon, "Treatment of alloxan-induced diabetic rats with metformin or glitazones is associated with amelioration of hyperglycaemia and neuroprotection," The Open Diabetes Journal, vol. 5, no. 1, pp. 8-12, 2012. 

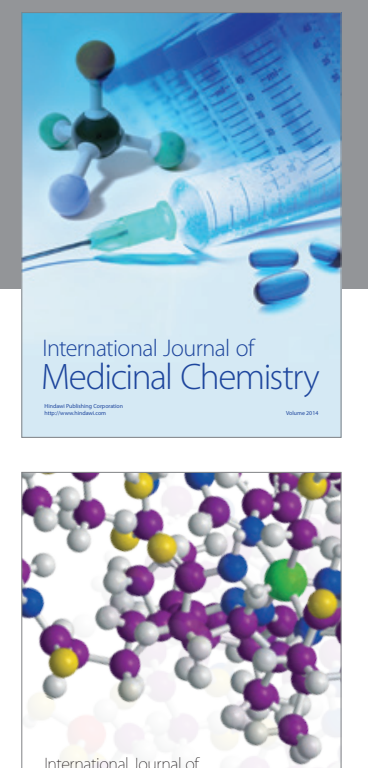

\section{Carbohydrate} Chemistry

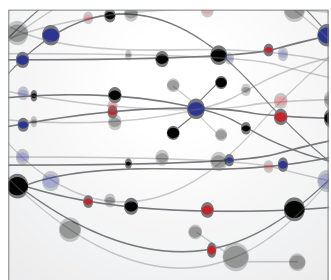

The Scientific World Journal
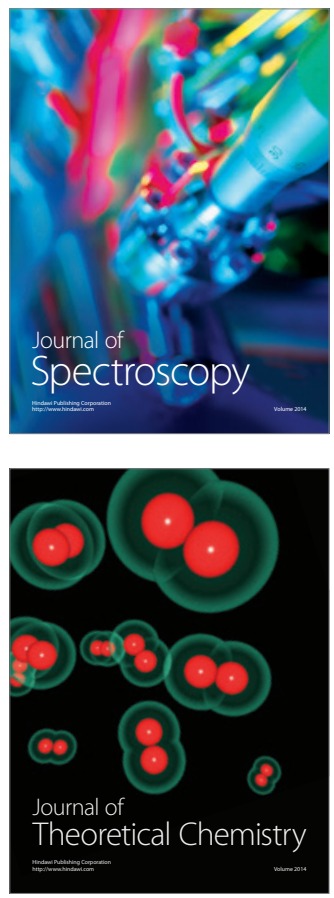
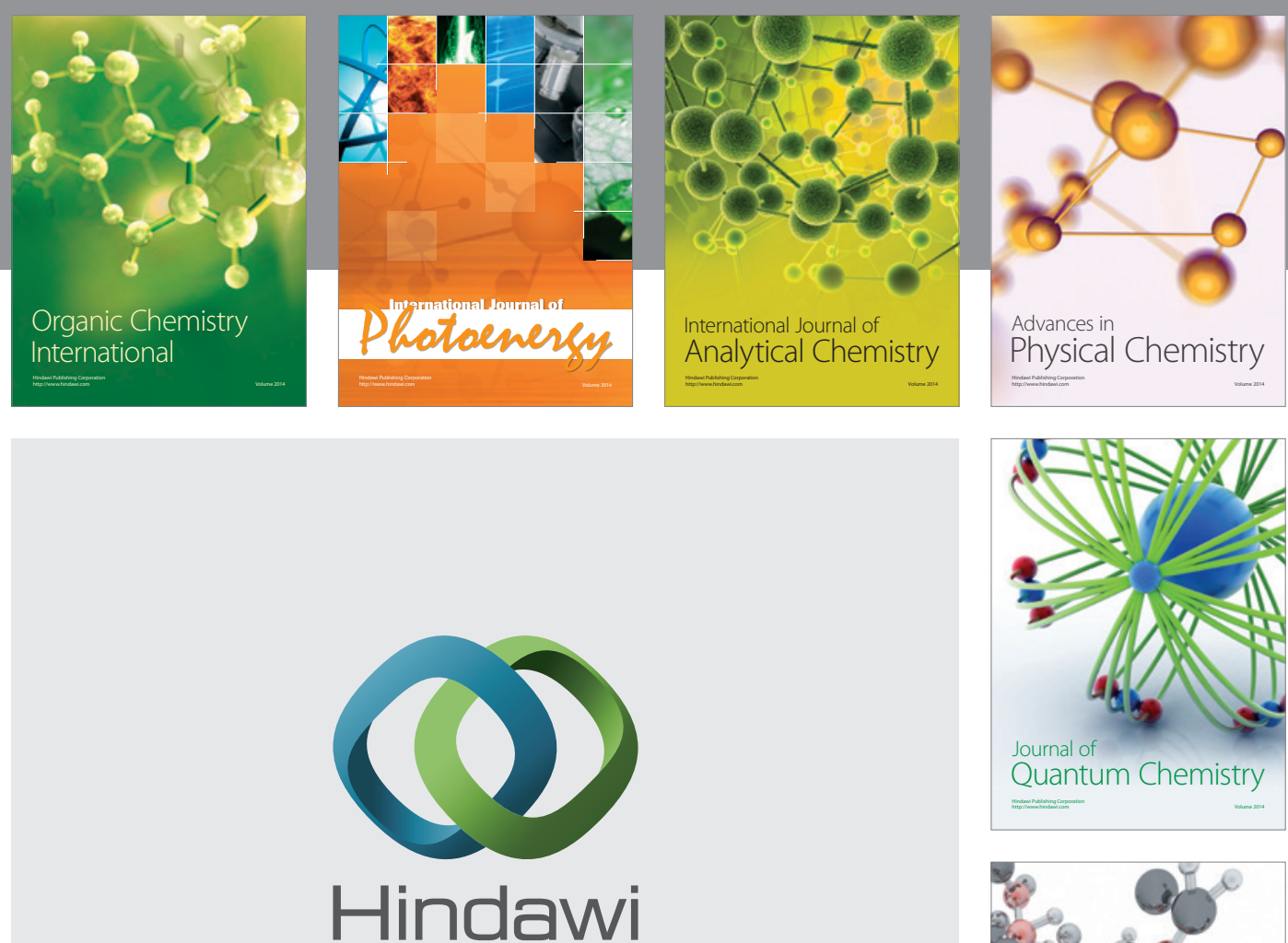

Submit your manuscripts at

http://www.hindawi.com

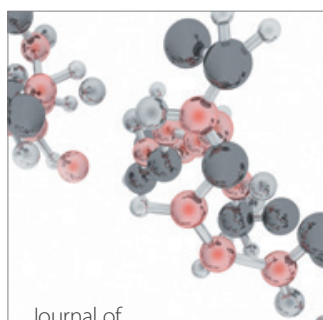

Analytical Methods

in Chemistry

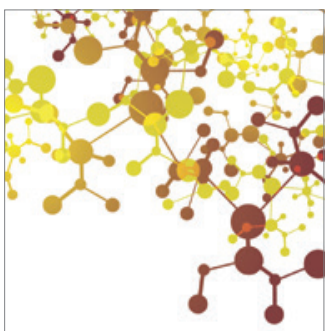

Journal of

Applied Chemistry

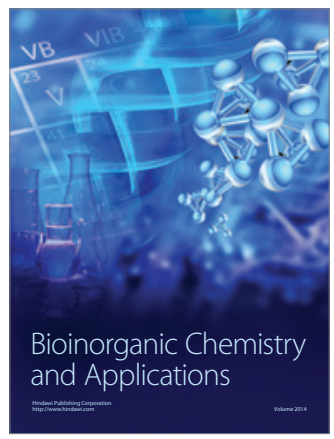

Inorganic Chemistry
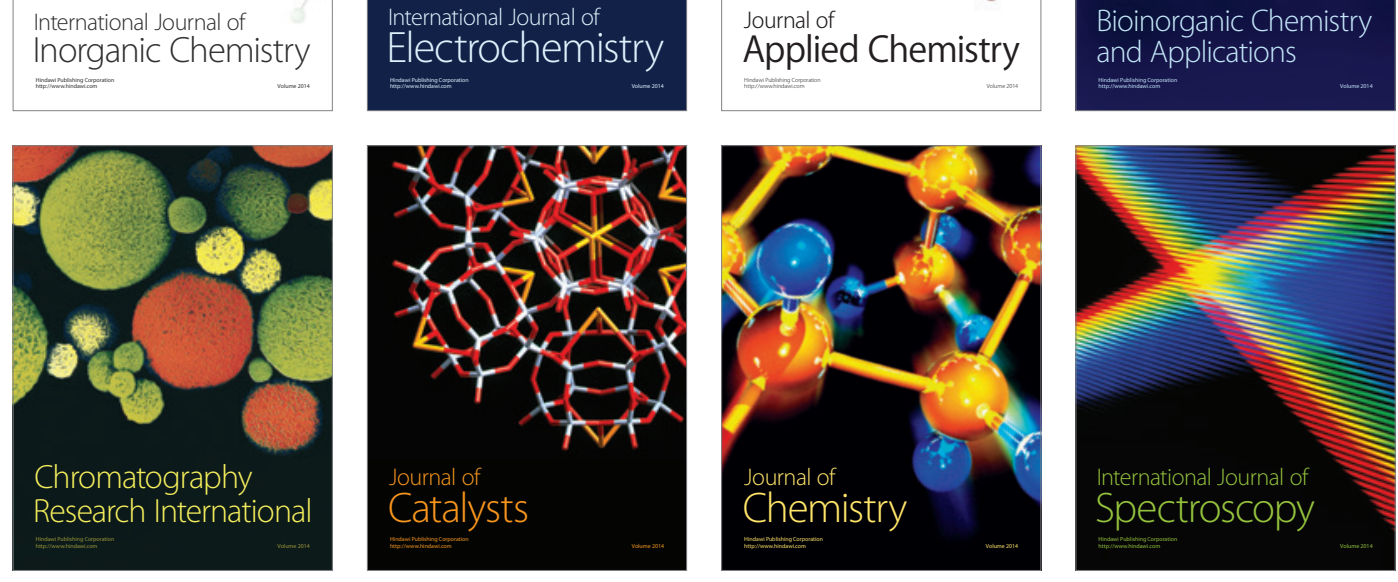